\title{
Ex vivo vibro-acoustography characterization of osteoporosis in an experimental mice model
}

\author{
Paulo Moraes Agnollitto ${ }^{1,2}$, Guilherme de Araújo Braz ${ }^{3} \wedge$, Adriano Levi Spirlandeli ${ }^{1}$, \\ Francisco José Albuquerque de Paula ${ }^{1} \wedge$, Antonio Adilton Oliveira Carneiro ${ }^{3 \wedge}$, Marcello Henrique Nogueira-Barbosa $^{1,2 \wedge}$ \\ ${ }^{1}$ Ribeirão Preto Medical School, University of São Paulo, Ribeirão Preto, SP, Brazil; ${ }^{2}$ Ribeirão Preto Medical School Musculoskeletal Imaging \\ Research Laboratory, Ribeirão Preto, SP, Brazil; ${ }^{3}$ Physics Department, Faculdade de Filosofia, Ciências e Letras de Ribeirão Preto, University of São \\ Paulo, Ribeirão Preto, SP, Brazil
}

Correspondence to: Paulo Moraes Agnollitto, MD. Ribeirão Preto Medical School, University of São Paulo, Av. Bandeirantes, 3900, Ribeirão Preto, SP, CEP 14048-900, Brazil. Email: pmagnollitto@alumni.usp.br.

\begin{abstract}
Background: Osteoporosis is a highly prevalent multifactorial osteometabolic disease, classically diagnosed, in vivo, by dual energy X-ray absorptiometry (DXA). This study evaluated osteoporosis, ex vivo, using vibroacoustography (VA), an elastographic technique based on ultrasound radiation force.

Methods: Three groups of mice femurs were used: (I) control group (CG), (II) osteoporosis group (OG) and (III) treated osteoporosis group (TOG), in which the animals received pamidronate, an antiresorptive drug. Evaluation was performed in an acoustic tank, using two high frequency focused beams produced by a confocal ultrasonic transducer. A hydrophone registered the low frequency acoustic response (AR) of bone samples. We used micro-computed tomography (microCT) as the reference standard and evaluated the correlation between VA and microCT parameters.
\end{abstract}

Results: The spectral analyses of the ARs with estimated area under the curve (AUC) values (mean; st. dev.) were, respectively, $1.29 \mathrm{e}^{-07}$ and $9.32 \mathrm{e}^{-08}$ for the CG, 3.25 $\mathrm{e}^{-08}$ and $2.16 \mathrm{e}^{-08}$ for the OG, and $1.50 \mathrm{e}^{-07}$ and $8.37 \mathrm{e}^{-08}$ for the TOG. VA differentiated the experimental groups $(\mathrm{P}<0.01)$ and the results were reproducible [interclass correlation coefficient (ICC): 0.43 (95\% CI: 0.15-0.71)]. There was also a statistically significant association between VA and microCT connectivity (Conn.) $(\mathrm{r}=0.80 ; \mathrm{P}<0.01)$ and connectivity density (Conn. D) ( $\mathrm{r}=0.76$; $\mathrm{P}<0.01)$.

Conclusions: These results encourage further studies aimed at evaluating the potential use of VA for the diagnosis of osteoporosis as a relatively low-cost and radiation-free alternative to DXA.

Keywords: Vibro-acoustography (VA); osteoporosis; ultrasound; micro-computed tomography (microCT); mice

Submitted Apr 24, 2020. Accepted for publication Sep 11, 2020.

doi: 10.21037/qims-20-610

View this article at: http://dx.doi.org/10.21037/qims-20-610

\section{Introduction}

Bone tissue, like any other biological tissue (e.g., thyroid, breast or liver tissue), has mechanical properties that can be altered by several pathological conditions $(1,2)$. Ultrasound is widely used as a suitable imaging modality to assess these mechanical properties of biological tissues. Conventional techniques of ultrasound, such as B-mode, are the most widely used in diagnostic imaging, having an exceptional capacity to evaluate soft tissues. Currently, it is well known that tissues that have high acoustic impedance are an obstacle for conventional ultrasonography (3),

\footnotetext{
^ ORCID: Paulo Moraes Agnollitto, 0000-0003-1818-3266; Guilherme de Araújo Braz, 0000-0003-3650-6145; Francisco José Albuquerque de Paula, 0000-0003-1262-3486; Antonio Adilton Oliveira Carneiro, 0000-0002-1752-7170; Marcello Henrique Nogueira-Barbosa, 0000-0002-7436-5315.
} 
therefore a comprehensive ultrasound evaluation of bone tissue encounters significant limitations because of the high acoustic impedance of cortical bone, which prevents the propagation of ultrasound waves (4-6). Nevertheless, several papers have introduced and highlighted the usefulness of conventional ultrasound techniques to assess bone abnormalities, mainly by addressing the study of its surface (7-11) or by emphasizing the evaluation of epiphyseal or apophyseal cartilaginous tissues in the pediatric population $(12,13)$. In addition, recent developments in ultrasound imaging technologies, such as elastography, are changing this scenario.

Elastography is an imaging modality that can be used for medical purposes, as it can measure tissue's elastic parameters ("stiffness"), resembling manual palpation, with the advantage of being a quantitative method $(14,15)$. There are numerous elastographic techniques, mainly differing in how the target is excited and/or how the response is acquired. Some of these techniques are in developmental stages and others have already reached clinical practice (16-21). Some elastographic techniques are based on ultrasound radiation force interacting with a target and producing low frequencies vibrations, called acoustic response (AR), which carries mechanical properties of the target. Fatemi and Greenleaf proposed one such technique: vibro-acoustography (VA) $(22,23)$. The VA technique consists of focusing two acoustic primary beams emitted at close frequencies, which creates a localized low frequency radiation beam on the studied object and using a hydrophone to register the low frequency acoustic emissions. Silva and Mitri demonstrated that, in VA, in addition to the radiation force, the two beams interact nonlinearly, giving rise to harmonics of the primary waves (24). Due to the interaction of focused and modulated beams, VA is very sensitive to morphology and internal structure of the target.

Osteoporosis is a highly prevalent multifactorial osteometabolic disease, characterized by a reduction in bone mass and associated with changes in bone microarchitecture (25-27). The most important consequence of osteoporosis is a reduction in the mechanical strength of bones, which increases the risk of fractures. Since 1994, the World Health Organization (WHO) has defined the operational diagnosis of osteoporosis based on the measurement of bone mineral density (BMD) (28-30). Dual energy X-ray absorptiometry (DXA) is the gold standard method for BMD measurement in vivo (31). The DXA methodology consists of estimating the attenuation of two $\mathrm{X}$-ray beams (with high and low energy) in bones and soft tissues. DXA predicts the susceptibility to fracture based only on low bone mass, but fragility fractures may occur in subjects showing a large spectrum of BMD values, including individuals with BMD within normal values. Alternatively, several methods are available to evaluate detailed characteristics of the bone microarchitecture, but they are either invasive and time-consuming (bone histomorphometry) or expensive and involve $\mathrm{X}$-ray radiation (high resolution peripheral computed tomography).

Micro-computed tomography (microCT), on the other hand, is the gold standard for measurement and visualization of bone structure in vitro and in preclinical animal studies. It allows visualization of the three-dimensional (3D) nature of the bone structure and also highly accurate quantification of bone structural parameters. The most important microCT parameters are bone volume fraction (BV/TV), trabecular thickness (Tb. Th), trabecular separation (Tb. $\mathrm{Sp}$ ), trabecular number (Tb. N), connectivity (Conn.) and connectivity density (Conn. D) for cancellous bone, and cortical bone volume and thickness for cortical bone (32). Conn. is a $3 \mathrm{D}$ property that describes the various connections between the so-called nodes (the structural units that represent the confluence of three or more trabeculae) and the connecting segments. Conn. is an index developed to characterize the redundancy of trabecular connections, and it is derived from the Euler number (33), which is a fundamental topologic measure counting the number of objects, the number of marrow cavities fully surrounded by bone, and the number of connections that must be broken to split the structure in two parts. Because it depends on structure size, it can also be expressed as density (Conn. D), when divided by the total volume $(34,35)$. MicroCT has a limited role for in vivo studies due to the small field of view and high dose of radiation (36).

The goal of our study was to assess the diagnostic potential of VA in osteoporosis and for this purpose, we have evaluated bone tissue ex vivo using microCT as the reference standard.

\section{Methods}

This study was conducted using mice femurs obtained from a previous experimental study conducted in our laboratory (37) and approved by the Institutional Animal Care and Use Committee of the Ribeirão Preto Medical School, University of São Paulo (protocol no. 111/2011). New committee approval was waived because no new experiment with animals was necessary. 


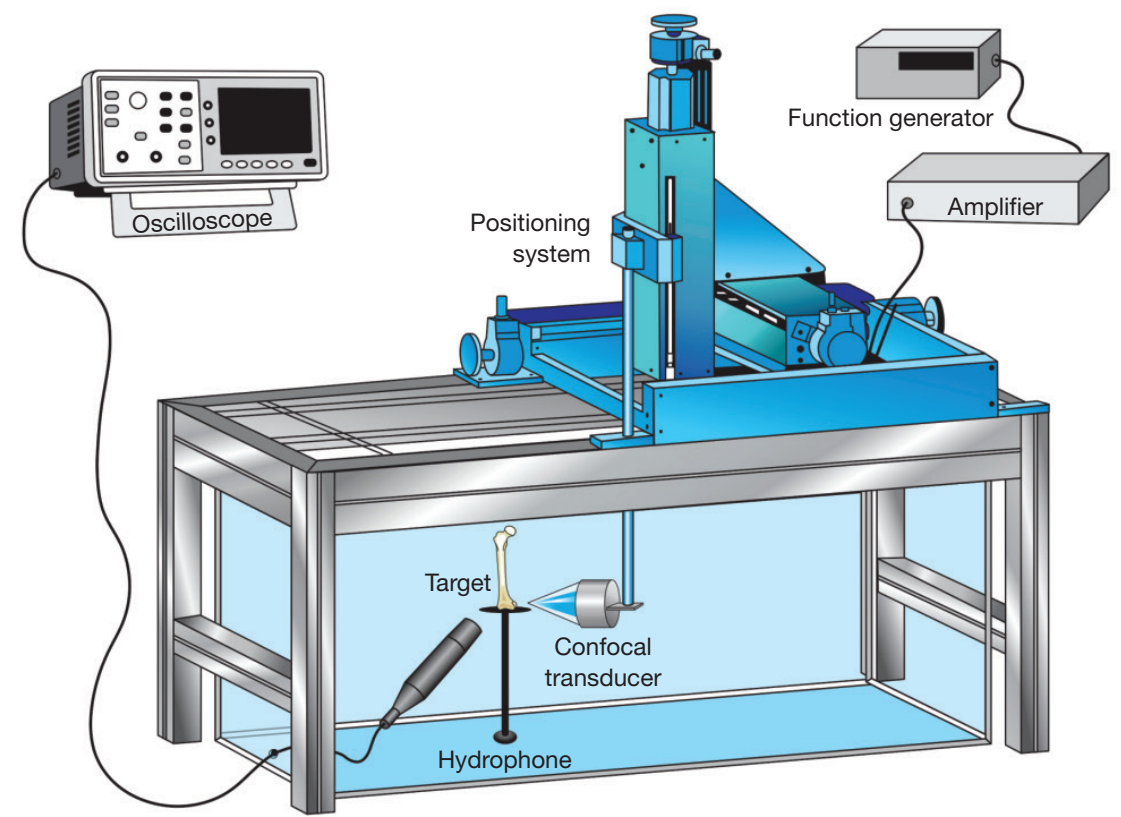

Figure 1 Experimental setup in the acoustic tank for the VA technique is shown. VA, vibro-acoustography.

\section{Study design and animals}

The study design included femurs from three groups of mice: (I) a control group (CG), with six specimens, (II) a group with induced osteoporosis (OG), with six specimens submitted to intraperitoneal injections of carbon tetrachloride $\left(\mathrm{CCl}_{4}\right.$-Sigma-Aldrich, Saint Louis, Missouri, United States) and (III) a group with induced osteoporosis treated with pamidronate (TOG), with five specimens submitted to intraperitoneal injections of $\mathrm{CCl}_{4}$ followed by treatment with pamidronate (Eurofarma, Ribeirão Preto, SP, Brazil), an antiresorptive drug.

Five-week-old male mice weighing approximately $18 \mathrm{~g}$ were used in our experiments. The animals were housed in cages in a room with controlled humidity and temperature $\left(23 \pm 1{ }^{\circ} \mathrm{C}\right)$ conditions and with an artificial light/dark cycle of 12 hours (lights on: 06:00 am-06:00 pm). The animals had free access to tap water and pellet chow. To induce hepatic osteodystrophy (HO), which was our model of induced osteoporosis, the mice were treated with $\mathrm{CCl}_{4}$ ( $1 \mathrm{~mL} / \mathrm{kg}$ body weight) dissolved in olive oil 1:4 (v:v) administered via intraperitoneal injection twice per week, as adapted from previous studies in this line of investigation $(38,39)$. At the end of the 8 -week period of $\mathrm{CCl}_{4}$ injections, a 2-week interval was allowed for the consolidation of hepatic disease. Mice in the TOG group were then treated with an intraperitoneal injection pamidronate dissolved in
$0.9 \% \mathrm{NaCl}$ at $1.25 \mathrm{mg} / \mathrm{kg}$ at the end of the fourth week. Mortality rate was $25 \%$ in the groups of mice receiving the intraperitoneal injection of $\mathrm{CCl}_{4}$, and this rate was not influenced by the additional administration of pamidronate. At the end of the tenth week, the mice were euthanized by cervical dislocation, following the guidelines of the local Institutional Animal Care and Use Committee.

\section{Experiments and VA}

The experiments with VA were conducted in an acoustic tank with degassed water under controlled temperature $\left(23{ }^{\circ} \mathrm{C}\right)$ (Figure 1). In the VA technique, performed in the tone burst mode, a confocal ultrasonic transducer (two piezoelectric elements; focus of $5 \mathrm{~cm}$; lateral resolution of $0.7 \mathrm{~mm}$ and focal zone of $1 \mathrm{~cm}$ ) generates two high frequency (3.200 and $3.265 \mathrm{MHz}$ ) focused beams, with a frequency difference of $65 \mathrm{kHz}$ between them (beating frequency). The transducer crystals were excited by function generators (Model 33220A, Keysight, Santa Rosa, California, United States). The two beams interact with each other at focus on the bone sample, producing a low frequency AR that is registered by a hydrophone (Model ITC-6050C, International Transducer Corporation, Santa Barbara, California, United States) (Figure 2). The AR signals were windowed and processed with the fast Fourier 


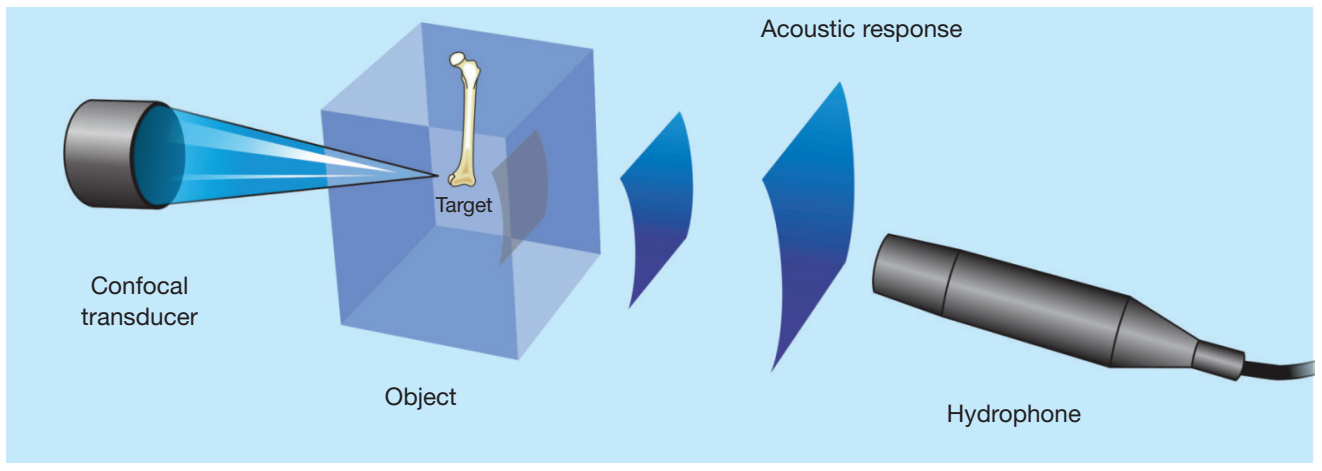

Figure 2 A schematic illustration of the AR being captured by the hydrophone is shown. AR, acoustic response.

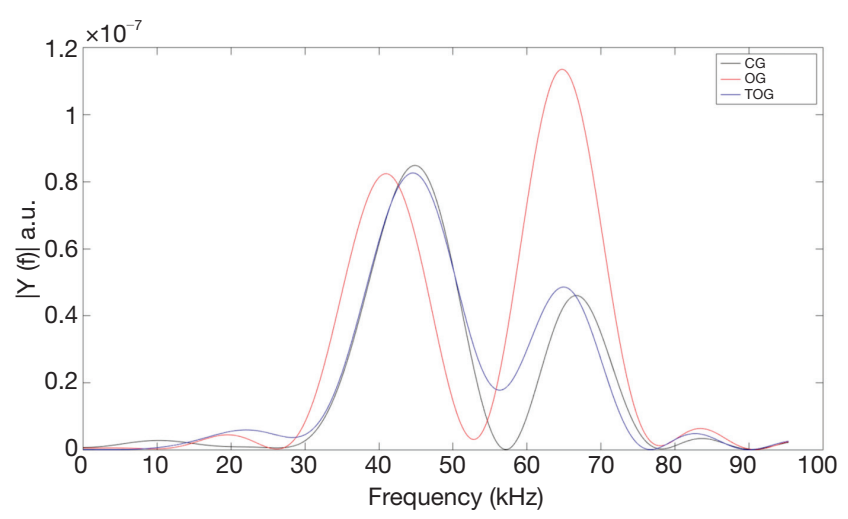

Figure 3 VA spectral curves representing the experimental groups: CG (black line), OG (red line) and TOG (blue line) is shown. $|\mathrm{Y}(\mathrm{f})|$ represents the module of the fast Fourier Transform of the acoustic signals multiplicated by its complex conjugate, expressed in a.u. VA, vibro-acoustography; CG, control group; OG, osteoporosis group; TOG, treated osteoporosis group; a.u., arbitrary units.

transform (Figure 3). In order to obtain numerical values carrying information about the mechanical properties of the samples, the area under the curve (AUC) was estimated in an interval centered at $65 \mathrm{kHz}$ with a width of $5 \mathrm{kHz}$ (VAAUC). The experiments were repeated three times in order to test reproducibility.

\section{MicroCT}

Mice femurs were scanned using a microCT instrument (Model 1172, SkyScan, Kontich, Antwerp, Belgium). The morphometric parameters selected for the analysis of bone microarchitecture are described in Table 1. All the parameters were named according to the Parfitt's system (40).
These parameters were determined in the distal portion of the femurs, starting $0.25 \mathrm{~mm}$ proximal to the distal growth plate and covering a total length of $1 \mathrm{~mm}$. Cortical bone was manually excluded, separating only the trabecular bone, since osteoporosis affects primarily this region of the bone in the early stages of the disease (41). The bones were scanned with an energy level of $55 \mathrm{kVp}$, tube current of $145 \mathrm{~mA}$ and a voxel of $5.0 \mathrm{~mm}^{3}(32,36)$. The equipment underwent a weekly programmed calibration, with phantoms presenting with densities of 0.25 and $0.75 \mathrm{mg} / \mathrm{cm}^{3}$. CT-analyzer software (version 1.13.2.1) was used for the quantitative assessment and CTVol (version 2.2.3.0) and Dataview (version 1.4.4.0) software were used to reconstruct images of the bones. The results are expressed according to the standard nomenclature (36).

\section{Statistical analysis}

The results obtained for the three groups were compared using ANOVA followed by Tukey's post-hoc test. The reproducibility of the experiments was assessed using the interclass correlation coefficient (ICC), and Spearman's coefficient was used to determine the correlation between two parameters. The statistical analysis was performed using SAS (version 9.2; SAS, Cary, North Carolina; United States) and R (version 3.4.1; The R Project for Statistical Computing; General Public License) software. A P value less than 0.05 was considered statistically significant.

\section{Results}

\section{VA spectral analysis and group differentiation}

The VA spectral analysis of the mean of each group is shown in Figure 3, while numerical values of VA-AUC, are 
Table 1 Definition and description of trabecular bone microarchitecture according to Parfitt et al. 1987

\begin{tabular}{lll}
\hline Abbreviations & Variables & Description \\
\hline BV/TV & Bone volume fraction & Ratio of segmented bone volume to total volume of the region of interest \\
Tb. Th & Trabecular thickness & Mean thickness of trabeculae, assessed using direct 3D methods \\
Tb. N & Trabecular number & Average number of trabeculae per unit length \\
Tb. Sp & Trabecular separation & Mean distance between trabeculae assessed using direct 3D methods \\
Conn. D & Connectivity density & $\begin{array}{l}\text { A measure of the degree of connectivity of trabeculae normalized by TV (total } \\
\text { volume of the region of interest) }\end{array} \quad$ 1/mm $\mathrm{mm}^{3}$ \\
\hline
\end{tabular}

Table 2 Numerical results for the VA-AUC

\begin{tabular}{llcc}
\hline Group & N & Mean & St. dev. \\
\hline CG & 6 & $1.29 \mathrm{e}^{-07}$ & $9.32 \mathrm{e}^{-08}$ \\
OG & 6 & $3.25 \mathrm{e}^{-08}$ & $2.16 \mathrm{e}^{-08}$ \\
TOG & 5 & $1.50 \mathrm{e}^{-07}$ & $8.37 \mathrm{e}^{-08}$ \\
\hline
\end{tabular}

VA-AUC, vibro-acoustography area under the curve estimation; CG, control group; OG, osteoporosis group; TOG, treated osteoporosis group.

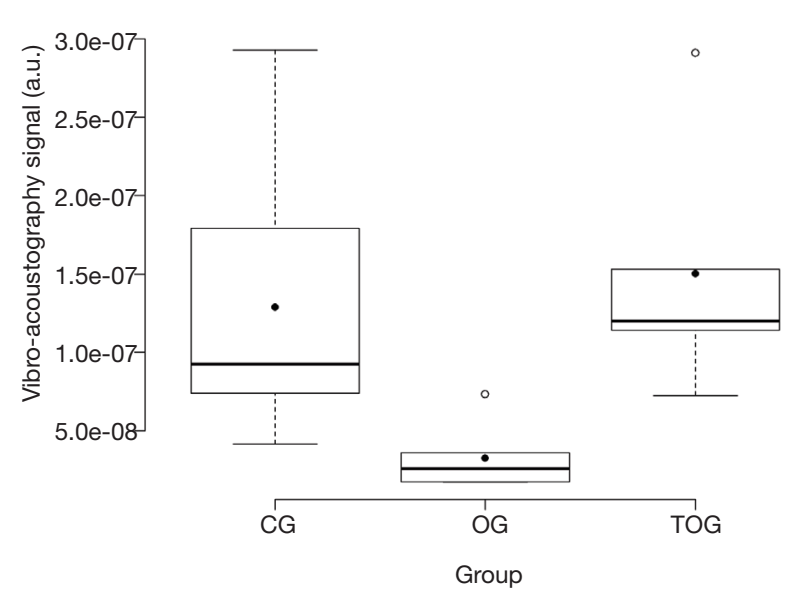

Figure 4 Box plot of VA-AUC for each experimental group showing that OG was different from CG and from TOG, with statistical significance $(\mathrm{P}<0.01)$. TOG and $C G$ showed no statistical difference. VA-AUC, vibro-acoustography area under the curve estimation; OG, osteoporosis group; CG, control group; TOG, treated osteoporosis group; a.u., arbitrary units.

shown in Table 2. A box plot of the experimental results is shown in Figure 4. ANOVA with Tukey's post-hoc test demonstrated that VA was able to differentiate between the three experimental groups $(\mathrm{P}<0.01)$, and the results were reproducible [ICC: 0.43 (95\% CI: 0.15-0.71)].

\section{MicroCT}

MicroCT assessment of the three experimental groups are depicted in Table 3, and $3 \mathrm{D}$ render volumetric reconstructions of the trabecular anatomy, associated with corresponding axial slice of a specimen of each experimental group are shown in Figure 5.

\section{Correlation between VA measurements and microCT parameters}

The VA/microCT correlations are listed in Table 4. There was a strong correlation between VA and microCT Conn. $(\mathrm{r}=0.80 ; \mathrm{P}<0.01)$ and Conn. $\mathrm{D}(\mathrm{r}=0.76 ; \mathrm{P}<0.01)$, as shown in Figure 6.

\section{Discussion}

Our results show that VA differentiated the OG from the CG and also the TOG from OG with statistical significance $(\mathrm{P}<0.01)$. The TOG and the $C G$ showed a similar mechanical behavior, without statistical difference, which is in agreement with microCT parameters. The VA results were reproducible and moreover, there was a strong correlation between VA-AUC and the microarchitectural parameters measured by microCT (42), such as Conn. $(\mathrm{r}=0.80 ; \mathrm{P}<0.01)$ and Conn. $\mathrm{D}(\mathrm{r}=0.76 ; \mathrm{P}<0.01)$. 
Table 3 MicroCT parameters

\begin{tabular}{|c|c|c|c|c|c|c|}
\hline Parameters & \multicolumn{2}{|c|}{ CG } & \multicolumn{2}{|c|}{ OG } & \multicolumn{2}{|c|}{ TOG } \\
\hline BV/TV (\%) & 11.961 & 3.47 & 10.398 & 3.53 & 12.886 & 4.44 \\
\hline Tb. Th (mm) & 0.054 & 0.009 & 0.052 & 0.006 & 0.047 & 0.005 \\
\hline Tb. N (1/mm) & 2.287 & 0.28 & 1.679 & 0.14 & 2.532 & 0.70 \\
\hline Conn. & 598.00 & 175.11 & 358.00 & 136.54 & $3,086.83$ & $1,109.78$ \\
\hline Conn. D $\left(1 / \mathrm{mm}^{3}\right)$ & 264.84 & 79.13 & 172.66 & 51.50 & $1,452.19$ & 504.83 \\
\hline
\end{tabular}

MicroCT, micro-computed tomography; CG, control group; OG, osteoporosis group; TOG, treated osteoporosis group; BV/TV, bone volume fraction; Tb. Th, trabecular thickness; Tb. N, trabecular number; Tb. Sp, trabecular separation; Conn., connectivity; Conn. D, connectivity density.

A

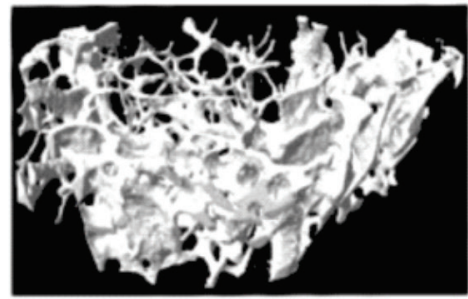

B

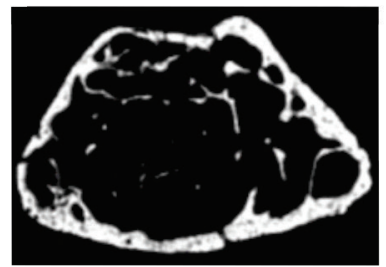

$\mathrm{OG}$
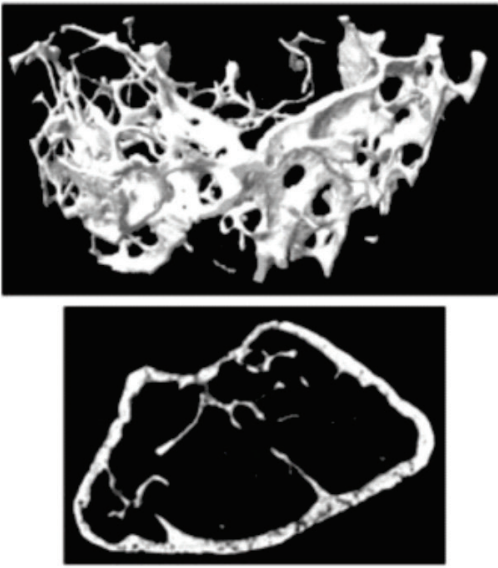

TOG
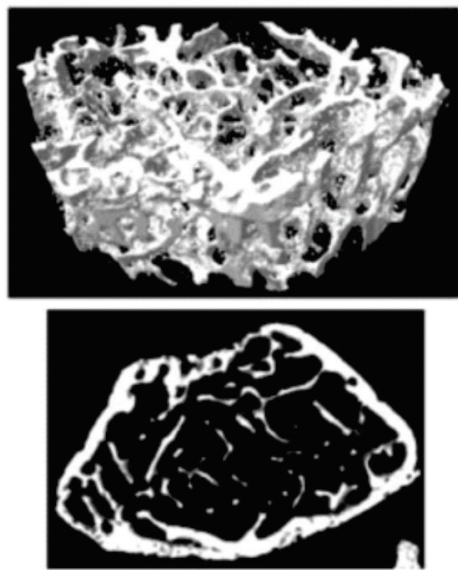

Figure 5 Representative microCT images of each experimental group. (A) Reconstructions with volume rendering showing the tridimensional microstructure of trabecular bone; (B) axial sections of the distal portion of the femurs. microCT, micro-computed tomography; CG, control group; OG, osteoporosis group; TOG, treated osteoporosis group.

Table 4 Correlations between VA-AUC and microCT parameters

\begin{tabular}{lcc}
\hline Parameters & Spearman's coefficient $(r)$ & P value \\
\hline BV/TV $(\%)$ & 0.19 & 0.47 \\
Tb. Th $(\mathrm{mm})$ & -0.34 & 0.20 \\
Tb. N $(1 / \mathrm{mm})$ & 0.52 & 0.06 \\
Tb. Sp $(\mathrm{mm})$ & -0.49 & 0.06 \\
Conn. & 0.80 & $<0.01$ \\
Conn. D & 0.76 & $<0.01$ \\
\hline
\end{tabular}

VA-AUC, vibro-acoustography area under the curve estimation; microCT, micro-computed tomography; BV/TV, bone volume fraction; Tb.

Th, trabecular thickness; Tb. N, trabecular number; Tb. Sp, trabecular separation; Conn., connectivity; Conn. D, connectivity density. 
A

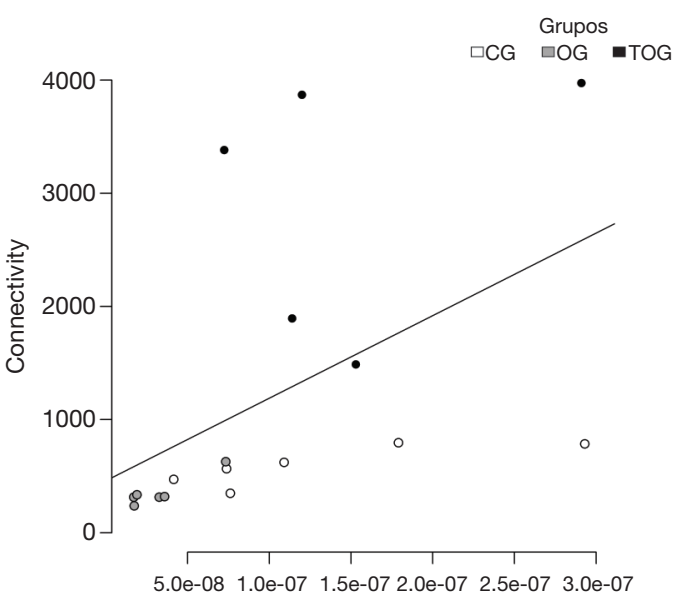

Vibro-acoustography signal (a.u.)
B

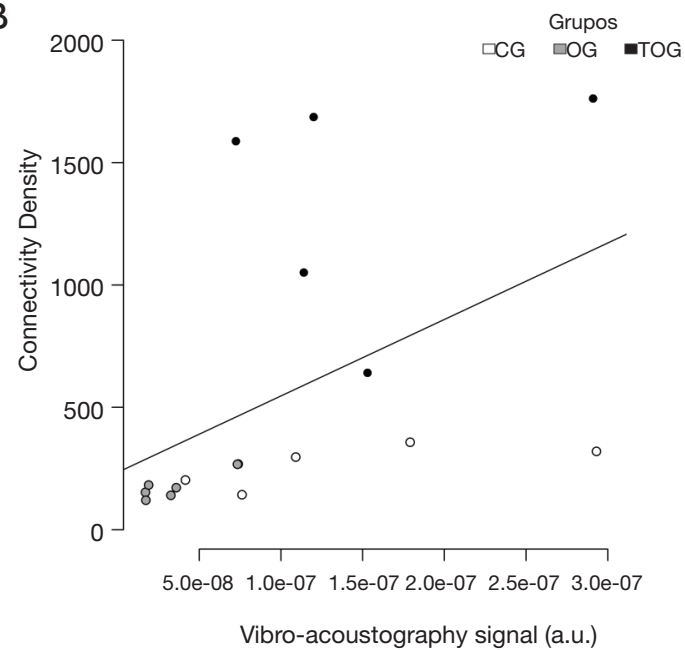

Figure 6 Scatter plots showing statistically significant correlations between VA-AUC and microCT in (A) Conn. $(r=0.80 ; P<0.01)$ and (B) Conn. D ( $r=0.76$; $\mathrm{P}<0.01)$. VA-AUC, vibro-acoustography area under the curve estimation; microCT, micro-computed tomography; Conn., connectivity; Conn. D, connectivity density; CG, control group; OG, osteoporosis group; TOG, treated osteoporosis group; a.u., arbitrary units.

A

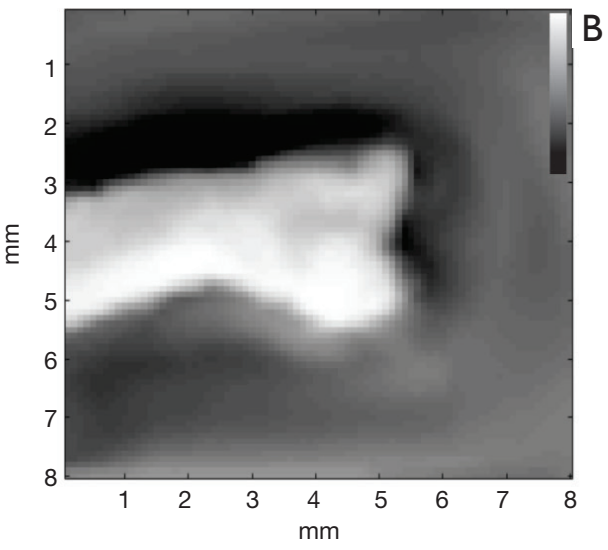

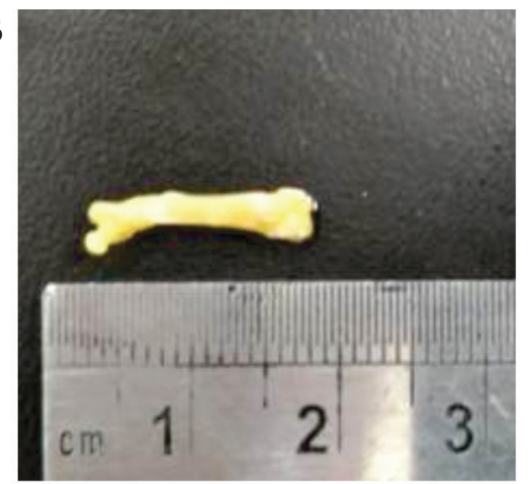

Figure 7 VA image of mice femurs in grayscale (A) with the corresponding experimental specimen (B). VA, vibro-acoustography.

The acquisition time for the quantitative measurements was approximately 5 minutes per specimen, but this could be shortened with the implementation of VA in clinical systems (43) and by using a multielement transducer (44). The most important potential benefit of using VA for the diagnosis of osteoporosis in vivo would be to prevent patient exposure to ionizing radiation, which is inherent to $\mathrm{X}$-ray techniques such as DXA. As previously demonstrated by our group (45), VA can also be used to produce images of bone tissue. As an addendum to this study, we have imaged one of the femurs in the CG, and this image is shown in Figure 7, along with the corresponding specimen. The mean acquisition time for these images was approximately 1 hour, using the same experimental setup. Taken together, these results show the potential use of VA not only as a diagnostic tool for osteoporosis but also as a test to monitor posttreatment improvement.

HO was our experimental model for studying osteoporosis. $\mathrm{HO}$ is an osteometabolic disease that presents with low BMD and changes in bone microarchitecture, and it constitutes a reasonable experimental model for evaluating osteoporosis (46). In this model, hepatic impairment leads to metabolic disturbances that causes loss of bone mass $(37,38,46,47)$, however the pathogenesis is not fully 
understood (48). Some studies have shown that decreased bone formation is the predominant mechanism (47), while others point to increased bone resorption as the main cause of bone loss (49). Bilateral oophorectomy, spinal cord lesion, immobilization and dietary manipulation are the most common methods used to induce experimental osteoporosis (50-56). While we did not use the most common models of experimental osteoporosis described in the literature, our trabecular bone loss was equivalent to these classical models, as depicted by our microCT results, that showed severe bone loss in the OG.

Quantitative ultrasonometry (QUS) is another ultrasound technique used to evaluate bone tissue, based on velocity and amplitude attenuation of ultrasound waves (57-59). QUS is not used to obtain images, but to measure and assess tissue properties $(60)$. This modality may be used to evaluate osteoporosis $(61,62)$ and fracture healing (63-65). QUS is a low-cost technique that has been applied at different anatomical sites, but according to the International Society for Clinical Densitometry (ISCD) official guideline (66) the only validated skeletal site is the calcaneus.

The VA technique has already been used to evaluate bone tissue (45,67-69), however most of these studies focused on qualitative aspects of bone tissue. In contrast, our study is the first successful attempt to show quantitative correlations between VA and microCT parameters, which is the gold standard for assessment and quantification of bone structure in experimental studies. Recently, Ghavami et al. (70) used VA to discriminate normal and osteoporotic bone in vivo in humans, illustrating the potential of this technique to reach clinical practice and to become an alternative diagnostic test to DXA, in the context of osteoporosis.

Our study has some noteworthy limitations. Firstly, we have tested a relatively limited number of specimens. In addition, the current setup is not suitable for clinical use. Furthermore, to the present moment, there is not a complete physical understanding of the VA interaction with bone tissue, and therefore, there is no certainty about what is really being measured, though it is probably related to the internal structure of the bone. Our group is working in physical models to better understand these phenomenons. Nevertheless, our preliminary results encourage further research and development to investigate the possible use of VA in vivo for the diagnosis of osteoporosis.

Our results show that VA can detect bone impairment in mice femurs with induced osteoporosis and might be useful to monitor post-treatment improvement of bone tissue. A positive correlation was observed between VA and microCT assessments. These results encourage further studies aimed at evaluating the potential use of VA for the diagnosis of osteoporosis as a relatively low-cost and radiation-free alternative to DXA.

\section{Acknowledgments}

We thank Agnelo dos Santos Bastos Neto for his technical support and Carolina de Freitas Lins, Estela Carneseca and Guilherme Zeri for their support in the preparation of this manuscript.

Funding: This study was financed in part by the Coordenação de Aperfeiçoamento de Pessoal de Nível Superior - Brasil (CAPES) - Finance Code 001. The authors also acknowledge the following funding sources: Conselho Nacional de Desenvolvimento Científico e Tecnológico - CNPq (grant 305610/2017-1), Finep (grant 2210/2008) and FAEPA (grant 819/2019).

\section{Footnote}

Conflicts of Interest: All authors have completed the ICMJE uniform disclosure form (available at http://dx.doi. org/10.21037/qims-20-610). MHNB serves as an unpaid editorial board member of Quantitative Imaging in Medicine and Surgery. The other authors have no conflicts of interest to declare.

Ethical Statement: This study was approved by the Institutional Animal Care and Use Committee of the Ribeirão Preto Medical School, University of São Paulo.

Open Access Statement: This is an Open Access article distributed in accordance with the Creative Commons Attribution-NonCommercial-NoDerivs 4.0 International License (CC BY-NC-ND 4.0), which permits the noncommercial replication and distribution of the article with the strict proviso that no changes or edits are made and the original work is properly cited (including links to both the formal publication through the relevant DOI and the license). See: https://creativecommons.org/licenses/by-nc-nd/4.0/.

\section{References}

1. Özkaya N, Leger D, Goldsheyder D, Nordin M. Mechanical properties of biological tissues. In: Özkaya N, Leger D, Goldsheyder D, Nordin M. Fundamentals of biomechanics: equilibrium, motion, and deformation. 
Cham: Springer International Publishing, 2017:361-87.

2. Saraf H, Ramesh KT, Lennon AM, Merkle AC, Roberts JC. Mechanical properties of soft human tissues under dynamic loading. J Biomech 2007;40:1960-7.

3. Cho KH, Lee YH, Lee SM, Shahid MU, Suh KJ, Choi JH. Sonography of bone and bone-related diseases of the extremities. J Clin Ultrasound 2004;32:511-21.

4. Cobbold RSC. Foundations of biomedical ultrasound. Oxford: Oxford University Press, 2007:802.

5. Macintyre NJ, Lorbergs AL. Imaging-based methods for non-invasive assessment of bone properties influenced by mechanical loading. Physiother Can 2012;64:202-15.

6. Wells PNT, Liang HD, Young TP. Ultrasonic imaging technologies in perspective. J Med Eng Technol 2011;35:289-99.

7. Baillet A, Gaujoux-Viala C, Mouterde G, Pham T, Tebib J, Saraux A, Fautrel B, Cantagrel A, Le Loët X, Gaudin P. Comparison of the efficacy of sonography, magnetic resonance imaging and conventional radiography for the detection of bone erosions in rheumatoid arthritis patients: a systematic review and meta-analysis. Rheumatology (Oxford) 2011;50:1137-47.

8. Griffith JF, Rainer TH, Ching AS, Law KL, Cocks RA, Metreweli C. Sonography compared with radiography in revealing acute rib fracture. AJR Am J Roentgenol 1999; 173:1603-9.

9. Jin W, Yang DM, Kim HC, Ryu KN. Diagnostic values of sonography for assessment of sternal fractures compared with conventional radiography and bone scans. J Ultrasound Med 2006;25:1263-8.

10. Li YQ, Jiang C, Li Y, Xu F, Xu KL, Ta DA, Le LH. Multilayer velocity model based synthetic aperture ultrasound imaging of cortical bone. Acta Phys Sin 2019;68:184302.

11. Renaud G, Kruizinga P, Cassereau D, Laugier P. In vivo ultrasound imaging of the bone cortex. Phys Med Biol 2018;63:125010.

12. Hryhorczuk AL, Restrepo R, Lee EY. Pediatric musculoskeletal ultrasound: practical imaging approach. AJR Am J Roentgenol 2016;206:W62-72.

13. Markowitz RI, Davidson RS, Harty MP, Bellah RD, Hubbard AM, Rosenberg HK. Sonography of the elbow in infants and children. AJR Am J Roentgenol 1992;159:829-33.

14. Ophir J, Céspedes I, Ponnekanti H, Yazdi Y, Li X. Elastography: a quantitative method for imaging the elasticity of biological tissues. Ultrason Imaging 1991;13:111-34.

15. Parker KJ, Doyley MM, Rubens DJ. Imaging the elastic properties of tissue: the 20 year perspective. Phys Med
Biol 2011;56:R1-29.

16. Almeida TWJ, Sampaio DRT, Bruno AC, Pavan TZ, Carneiro AAO. Comparison between shear wave dispersion magneto motive ultrasound and transient elastography for measuring tissue-mimicking phantom viscoelasticity. IEEE Trans Ultrason Ferroelectr Freq Control 2015;62:2138-45.

17. Catheline S, Thomas JL, Wu F, Fink MA. Diffraction field of a low frequency vibrator in soft tissues using transient elastography. IEEE Trans Ultrason Ferroelectr Freq Control 1999;46:1013-9.

18. Doherty JR, Trahey GE, Nightingale KR, Palmeri ML. Acoustic radiation force elasticity imaging in diagnostic ultrasound. IEEE Trans Ultrason Ferroelectr Freq Control 2013;60:685-701.

19. Sarvazyan A, Hall TJ, Urban MW, Fatemi M, Aglyamov SR, Garra BS. An overview of elastography - an emerging branch of medical imaging. Curr Med Imaging Rev 2011;7:255-82.

20. Sigrist RMS, Liau J, Kaffas A El, Chammas MC, Willmann JK. Ultrasound elastography: review of techniques and clinical applications. Theranostics 2017;7:1303-29.

21. Tang A, Cloutier G, Szeverenyi NM, Sirlin CB. Ultrasound elastography and mr elastography for assessing liver fibrosis: part 1, principles and techniques. AJR Am J Roentgenol 2015;205:22-32.

22. Fatemi M, Greenleaf JF. Ultrasound-stimulated vibroacoustic spectrography. Science 1998;280:82-5.

23. Fatemi M, Greenleaf JF. Vibro-acoustography: an imaging modality based on ultrasound-stimulated acoustic emission. Proc Natl Acad Sci U S A 1999;96:6603-8.

24. Silva GT, Mitri FG. Difference-frequency generation in vibro-acoustography. Phys Med Biol 2011;56:5985-93.

25. Compston J, Cooper A, Cooper C, Gittoes N, Gregson C, Harvey N, Hope S, Kanis JA, McCloskey EV, Poole KES, Reid DM, Selby P, Thompson F, Thurston A, Vine $\mathrm{N}$; National Osteoporosis Guideline Group (NOGG). UK clinical guideline for the prevention and treatment of osteoporosis. Arch Osteoporos 2017;12:43.

26. Golob AL, Laya MB. Osteoporosis. Med Clin North Am 2015;99:587-606.

27. Tarantino U, Iolascon G, Cianferotti L, Masi L, Marcucci G, Giusti F, Marini F, Parri S, Feola M, Rao C, Piccirilli E, Zanetti EB, Cittadini N, Alvaro R, Moretti A, Calafiore D, Toro G, Gimigliano F, Resmini G, Brandi ML. Clinical guidelines for the prevention and treatment of osteoporosis: summary statements and recommendations from the Italian Society for Orthopaedics and 
Traumatology. J Orthop Traumatol 2017;18:3-36.

28. Kanis JA, McCloskey EV, Johansson H, Cooper C, Rizzoli $\mathrm{R}$, Reginster JY. European guidance for the diagnosis and management of osteoporosis in postmenopausal women. Osteoporos Int 2013;24:23-57.

29. Kanis JA, Harvey NC, Cooper C, Johansson H, Odén A, McCloskey EV; Advisory Board of the National Osteoporosis Guideline Group. A systematic review of intervention thresholds based on FRAX: a report prepared for the National Osteoporosis Guideline Group and the International Osteoporosis Foundation. Arch Osteoporos 2016;11:25.

30. Nayak S, Edwards DL, Saleh AA, Greenspan SL. Systematic review and meta-analysis of the performance of clinical risk assessment instruments for screening for osteoporosis or low bone density. Osteoporos Int 2015;26:1543-54.

31. Tella SH, Gallagher JC. Prevention and treatment of postmenopausal osteoporosis. J Steroid Biochem Mol Biol 2014;142:155-70.

32. Campbell GM, Sophocleous A. Quantitative analysis of bone and soft tissue by micro-computed tomography: applications to ex vivo and in vivo studies. Bonekey Rep 2014;3:564.

33. Odgaard A, Gundersen HJG. Quantification of connectivity in cancellous bone, with special emphasis on 3-D reconstructions. Bone 1993;14:173-82.

34. Dalle Carbonare L, Valenti MT, Bertoldo F, Zanatta M, Zenari S, Realdi G, Lo Cascio V, Giannini S. Bone microarchitecture evaluated by histomorphometry. Micron 2005;36:609-16.

35. DeHoff RT, Aigeltinger EH, Craig KR. Experimental determination of the topological properties of threedimensional microstructures. J Microsc 1972;95:69-91.

36. Bouxsein ML, Boyd SK, Christiansen BA, Guldberg RE, Jepsen KJ, Müller R. Guidelines for assessment of bone microstructure in rodents using micro-computed tomography. J Bone Miner Res 2010;25:1468-86.

37. Spirlandeli AL, Dick-de-Paula I, Zamarioli A, Jorgetti V, Ramalho LNZ, Nogueira-Barbosa MH, Volpon JB, Jordão AA, Cunha FQ, Fukada SY, de Paula FJA. Hepatic osteodystrophy: the mechanism of bone loss in hepatocellular disease and the effects of pamidronate treatment. Clinics (Sao Paulo) 2017;72:231-7.

38. Pereira FA, Facincani I, Jorgetti V, Ramalho LN, Volpon JB, Dos Reis LM, de Paula FJ. Etiopathogenesis of hepatic osteodystrophy in Wistar rats with cholestatic liver disease. Calcif Tissue Int 2009;85:75-83.
39. Taveira AT, Pereira FA, Fernandes MI, Sawamura R, Nogueira-Barbosa MH, Paula FJ. Longitudinal evaluation of hepatic osteodystrophy in children and adolescents with chronic cholestatic liver disease. Braz J Med Biol Res 2010;43:1127-34.

40. Parfitt AM, Drezner MK, Glorieux FH, Kanis JA, Malluche H, Meunier PJ, Ott SM, Recker RR. Bone histomorphometry: standardization of nomenclature, symbols, and units. Report of the ASBMR Histomorphometry Nomenclature Committee. J Bone Miner Res 1987;2:595-610.

41. Osterhoff G, Morgan EF, Shefelbine SJ, Karim L, McNamara LM, Augat P. Bone mechanical properties and changes with osteoporosis. Injury 2016;47:S11-20.

42. Zou KH, Tuncali K, Silverman SG. Correlation and simple linear regression. Radiology 2003;227:617-22.

43. Urban MW, Chalek C, Kinnick RR, Kinter TM, Haider B, Greenleaf JF, Thomenius KE, Fatemi M. Implementation of vibro-acoustography on a clinical ultrasound system. IEEE Trans Ultrason Ferroelectr Freq Control 2011;58:1169-81.

44. Kamimura HAS, Urban MW, Carneiro AAO, Fatemi M, Alizad A. Vibro-acoustography beam formation with reconfigurable arrays. IEEE Trans Ultrason Ferroelectr Freq Control 2012;59:1421-31.

45. Nogueira-Barbosa MH, Kamimura HAS, Braz G, Agnollitto PM, Carneiro AAO. Preliminary results of vibro-acoustography evaluation of bone surface and bone fracture. Quant Imaging Med Surg 2017;7:549-54.

46. Barbu EC, Chițu-Tișu CE, Lazăr M, Olariu C, Bojincă M, Ionescu RA, Ion DA, Bădărău IA. Hepatic osteodystrophy: a global (re)view of the problem. Acta Clin Croat 2017;56:512-25.

47. Klein GL, Soriano H, Shulman RJ, Levy M, Jones G, Langman CB. Hepatic osteodystrophy in chronic cholestasis: evidence for a multifactorial etiology. Pediatr Transplant 2002;6:136-40.

48. Gatta A, Verardo A, Di Pascoli M, Giannini S, Bolognesi M. Hepatic osteodystrophy. Clin Cases Miner Bone Metab 2014;11:185-91.

49. Chen CC, Wang SS, Jeng FS, Lee SD. Metabolic bone disease of liver cirrhosis: is it parallel to the clinical severity of cirrhosis? J Gastroenterol Hepatol 1996;11:417-21.

50. Guedes PMSG, Zamarioli A, Botega II, Silva RABD, Issa JPM, Butezloff MM, Sousa YTCS, Ximenez JPB, Volpon JB. Undernutrition impairs the quality of growth plate and trabecular and cortical bones in growing rats1. Acta Cir Bras 2019;34:e201900301. 
51. Jee WS, Ma Y. Animal models of immobilization osteopenia. Morphologie 1999;83:25-34.

52. Jee WS, Yao W. Overview: animal models of osteopenia and osteoporosis. J Musculoskelet Neuronal Interact 2001;1:193-207.

53. Komori T. Animal models for osteoporosis. Eur J Pharmacol 2015;759:287-94.

54. Lelovas PP, Xanthos TT, Thoma SE, Lyritis GP, Dontas IA. The laboratory rat as an animal model for osteoporosis research. Comp Med 2008;58:424-30.

55. Volpon JB, Silva AV, Falcai MJ, Louzada MJ, Zamarioli A, Kotake BG, Issa JP. The osteogenic effects of swimming on bone mass, strength, and microarchitecture in rats with unloading-induced bone loss. Microsc Res Tech 2015;78:784-91.

56. Zamarioli A, Battaglino RA, Morse LR, Sudhakar S, Maranho DA, Okubo R, Volpon JB, Shimano AC. Standing frame and electrical stimulation therapies partially preserve bone strength in a rodent model of acute spinal cord injury. Am J Phys Med Rehabil 2013;92:402-10.

57. Bernard S, Monteiller V, Komatitsch D, Lasaygues P. Ultrasonic computed tomography based on full-waveform inversion for bone quantitative imaging. Phys Med Biol 2017;62:7011-35.

58. Pereira D, Haïat G, Fernandes J, Belanger P. Effect of intracortical bone properties on the phase velocity and cutoff frequency of low-frequency guided wave modes (20-85 kHz). J Acoust Soc Am 2019;145:121-30.

59. Xu K, Minonzio JG, Ta D, Hu B, Wang W, Laugier P. Sparse SVD method for high-resolution extraction of the dispersion curves of ultrasonic guided waves. IEEE Trans Ultrason Ferroelectr Freq Control 2016;63:1514-24.

60. Barkmann R. Quantitative ultrasound. In: Barkmann R. Radiology of osteoporosis. Heidelberg: Springer Berlin Heidelberg, 2008:163-73.

61. Minonzio JG, Bochud N, Vallet Q, Ramiandrisoa D, Etcheto A, Briot K, Kolta S, Roux C, Laugier P.

Cite this article as: Agnollitto PM, Braz GA, Spirlandeli AL, de Paula FJA, Carneiro AAO, Nogueira-Barbosa MH. Ex vivo vibro-acoustography characterization of osteoporosis in an experimental mice model. Quant Imaging Med Surg 2021;11(2):586-596. doi: 10.21037/qims-20-610
Ultrasound-based estimates of cortical bone thickness and porosity are associated with nontraumatic fractures in postmenopausal women: a pilot study. J Bone Miner Res 2019;34:1585-96.

62. Rinaldo N, Pasini A, Donati R, Belcastro MG, GualdiRusso E. Quantitative ultrasonometry for the diagnosis of osteoporosis in human skeletal remains: New methods and standards. J Archaeol Sci 2018;99:153-61.

63. Barbieri G, Mazzer N, Ribeiro EA, Nogueira-Barbosa $\mathrm{MH}$, Barbieri CH. A comparative analysis between ultrasonometry and computer-aided tomography to evaluate bone healing. J Orthop Res 2012;30:1076-82.

64. Mandarano-Filho LG, Bezuti MT, Barbieri CH. In vivo standardization of bone ultrasonometry of the clavicle. Clinics (Sao Paulo) 2016;71:140-4.

65. Xu K, Ta D, He R, Qin YX, Wang W. Axial transmission method for long bone fracture evaluation by ultrasonic guided waves: simulation, phantom and in vitro experiments. Ultrasound Med Biol 2014;40:817-27.

66. 2019 Official Positions Adult. (cited 2020 Jul 21). Available online: https://iscd.app.box.com/s/5r713cfzvf4gr28q7zdcc g2i7169fv86

67. Alizad A, Walch M, Greenleaf JF, Fatemi M. Vibrational characteristics of bone fracture and fracture repair:

Application to excised rat femur. J Biomech Eng 2006;128:300-8.

68. Callé S, Remenieras JPP, Bou Matar O, Defontaine M, Patat FF. Application of nonlinear phenomena induced by focused ultrasound to bone imaging. Ultrasound Med Biol 2003;29:465-72.

69. Urban MW, Alizad A, Aquino W, Greenleaf JF, Fatemi M. A review of vibro-acoustography and its applications in medicine. Curr Med Imaging Rev 2011;7:350-9.

70. Ghavami S, Denis M, Gregory A, Webb J, Bayat M, Kumar V, Fatemi M, Alizad A. Pulsed vibro-acoustic method for assessment of osteoporosis \& osteopenia: a feasibility study on human subjects. J Mech Behav Biomed Mater 2019;97:187-97. 